\title{
Is Holmium Laser Enucleation of the Prostate a Good Surgical Alternative in Benign Prostatic Hyperplasia Management? A Review Article
}

\author{
Amirreza Abedi', Mohammad Reza Razzaghi ${ }^{2}$, Amirhossein Rahavian', Ebrahim Hazrati ${ }^{3}$, Fereshte Aliakbari ${ }^{4}$, \\ Vahid Vahedisoraki ${ }^{5}$, Farzad Allameh ${ }^{2 *}$ \\ 'Urology Department, Shohada-e-Tajrish Hospital, Shahid Beheshti University of Medical Sciences, Tehran, Iran \\ ${ }^{2}$ Laser Application in Medical Science Research Center, Shahid Beheshti University of Medical Sciences, Tehran, Iran \\ ${ }^{3}$ School of Medicine, 501 Hospital (Imam Reza), AJA University of Medical Sciences, Tehran, Iran \\ ${ }^{4}$ Men's Health and Reproductive Health Research Center, Shahid Beheshti University of Medical Sciences, Tehran, Iran \\ ${ }^{5}$ Department of Urology, Hasheminejad Kidney Center, Iran University of Medical Sciences, Tehran, Iran
}

\author{
*Correspondence to \\ Farzad Allameh, MD-MPH; Laser \\ Application in Medical Science \\ Research Center, Shahid Beheshti \\ University of Medical Sciences, \\ Tehran, Iran. \\ Tel: +982122749221 \\ E-mail: \\ farzadallame@gmail.com
}

Published online March 15, 2020

\begin{abstract}
Several therapeutic approaches such as holmium laser enucleation of the prostate (HoLEP) have been introduced to relieve bladder outlet obstruction caused by benign prostatic hyperplasia $(\mathrm{BPH})$. Compared with other techniques including the transurethral resection of the prostate (TURP) and simple open prostatectomy, HoLEP results in a shorter hospital stay and catheterization time and fewer blood loss and transfusions. HoLEP is a size-independent treatment option for BPH with average gland size from $36 \mathrm{~g}$ to $170 \mathrm{~g}$. HoLEP is a safe procedure in patients receiving an anticoagulant and has no significant influence on the hemoglobin level. Also, HoLEP is an easy and safe technique in patients with a prior history of prostate surgery and a need for retreatment because of adenoma regrowth. The postoperative erectile dysfunction rate of patients treated with HoLEP is similar to TURP or open prostatectomy and about $77 \%$ of these patients experience loss of ejaculation. Patients with transitional zone volume less than $30 \mathrm{~mL}$ may suffer from persistent stress urinary incontinence following HoLEP so other surgical techniques like bipolar TURP are a good choice for these patients. In young patients, considering HoLEP with high prostate-specific antigen density and a negative standard template prostate biopsy, multiparametric MRI needs to be considered to exclude prostate cancer.

Keywords: Laser; Minimal invasive; HoLEP; Prostate surgery; Prostate hyperplasia; Transurethral resection of prostate.
\end{abstract}

\section{Introduction}

Benign prostatic hyperplasia $(\mathrm{BPH})$ is one of the most common medical problems in old men, occurring in about $80 \%$ of men by the 8 th decade of their life..$^{1-3}$ Open prostatectomy (OP) and transurethral resection of the prostate (TURP) have been the most common surgical approaches to $\mathrm{BPH}$ surgery. ${ }^{4}$ Despite the overall promising long-term results and low re-operation rates, these procedures have some minor and major adverse effects such as dysuria, urinary frequency, sexual dysfunction, TUR syndrome, and sepsis associated with peri-operative morbidity; therefore, other therapeutic approaches have been developed to reduce these side effects with the same functional results, including the plasmakinetic resection or enucleation of the prostate, the Holmium laser enucleation or resection of the prostate, and the photoselective vaporization of the prostate (PVP). ${ }^{4-8}$
The endoscopic management of $\mathrm{BPH}$ that causes bladder outlet obstruction (BOO) is divided into three major categories: vaporization, the resection of tissue, and enucleation. ${ }^{9}$

The Holmium laser has a good penetration depth, which helps in staunching blood; it is also used for other urologic surgeries, including urolithiasis, ${ }^{10,11}$ bladder tumor, ${ }^{6}$ genital skin lesion, ${ }^{12}$ and urethrotomy. ${ }^{13,14}$

The Holmium laser enucleation of the prostate (HoLEP) was introduced about 20 years ago as a surgical treatment for the lower urinary tract symptom (LUTS) resulting from $\mathrm{BPH} .{ }^{15}$

Despite some drawbacks such as a special equipment requirement and a steep learning curve, it seems that HoLEP is an efficient surgical approach to BPH. ${ }^{5}$ Therefore, we decided to review all aspects of this treatment in this study and list all the advantages and

Please cite this article as follows: Abedi A, Razzaghi MR, Rahavian A, Hazrati E, Aliakbari F, Vahedisoraki V, et al. Is holmium laser enucleation of the prostate a good surgical alternative in benign prostatic hyperplasia management? A review article. J Lasers Med Sci. 2020;11(2):197-203. doi:10.34172/jlms.2020.33. 
disadvantages of this treatment as much as possible.

\begin{abstract}
Mechanism of Action
The holmium: YAG (Ho: YAG) laser is a pulsed solid laser with a wavelength of $2140 \mathrm{~nm}$, which is absorbable by water and water-containing tissues, leading to a very short penetration depth into the (prostatic) tissue $(\sim 0.4 \mathrm{~mm}) .^{9}$ Therefore, depending on the distance between the end of the laser fiber and prostatic tissue, the surgeon will have hemostasis $(<3 \mathrm{~mm})$, or (in direct contact) cutting and vaporization of prostatic tissue. ${ }^{16,17}$ These properties turn the Ho: YAG laser into an ideal device to enucleate the prostatic lobes. ${ }^{9}$ The lower energy settings are applicable for reducing the chance of external urethral sphincter injury. A $550-\mu \mathrm{m}$ end-firing fiber is generally used. Lowpower and high-power lasers were used for HoLEP and a randomized controlled trial revealed no inferiority for the low-power laser in mean enucleation efficacy and postoperative dysuria, International Prostate Symptom Score (IPSS) and Q-max in a one-year follow-up. ${ }^{18}$

Two techniques have been described for HoLEP: the three-lobe technique and the two-lobe or en-bloc technique. Ho: YAG laser enucleation can be used according to the patient's individual prostate anatomy. ${ }^{19}$
\end{abstract}

\section{The Procedure of HoLEP and Morcellation}

HoLEP is very technical surgery and should be done by well-experienced urologists in well-equipped centers.

HoLEP is a stepwise procedure that should be performed precisely for expected outcomes. Kuo et al mentioned some steps as follows:

Step 1: Urethral calibration up to $30 \mathrm{Fr}$.

Step 2: The insertion of a 26-28 Fr continuous resectoscope and the visualization of the anatomy.

Step 3: The enucleation of prostate lobes. In trilobar hypertrophy, the median lobe should be enucleated first.

Step 4: The inspection of the prostatic fossa. After finishing enucleation and pushing the lobes into the bladder, the prostatic fossa and the capsular surface should be inspected carefully and all bleeding points should be coagulated to reach complete hemostasis because the dry fossa is necessary for the next step.

Step 5: A morcellator is introduced to the bladder via an outer resectoscope sheath and the morcellation of prostatic lobes is done and fragmented tissue is sucked by a vacuum pump. ${ }^{20}$

\section{Prostate Size}

The anatomy and size of the prostate are the most important factors when the surgical management of $\mathrm{BPH}$ is considered.

Many non-randomized researches have revealed that HoLEP is a size-independent treatment option for $\mathrm{BPH}$ with a mean adenoma size from $36 \mathrm{~g}$ to $170 \mathrm{~g} .{ }^{21-}$ ${ }^{23}$ Recently, a study has shown that in patients with a small prostate (30 g), HoLEP is as effective as PVP in improving voiding parameters and urinary symptoms. ${ }^{24}$ Furthermore, its efficacy in patients with prostates $>125$ $\mathrm{g}$ has been reported. ${ }^{25,26}$ A comparison between HoLEP and suprapubic prostatectomy has revealed that HoLEP is an effective and safe surgical approach in large prostate management, ${ }^{27,28}$ with similar amelioration regarding maximal urinary flowIPSS and re-treatment rates after 5 years (5\% vs. $6.7 \%$ respectively). ${ }^{27}$

A major limitation in patients with a very large prostate (up to $400 \mathrm{~g}$ ) is the capability of the equipment to reach the bladder neck. On the other hand, very large prostates are usually more difficult to morcellate and occasionally need cystotomy to take away the large enucleated adenomas. In that case, some urologists prefer to create a perineal urethrostomy which then allows the performance of HoLEP with a standard instrument. Other surgeons consider simple prostatectomy or robotic-assisted laparoscopic methods as an alternative to HoLEP. In terms of prostate shape, HoLEP is a shape independent surgical approach. Wisenbaugh et al reported similar outcomes of HoLEP in patients with bilobar and trilobar (including median lobe enlargement) prostate morphology. ${ }^{29}$

With increasing surgeons' experience, the time of enucleation decreased; however, the morcellation time is fixed because this is instrument and tissue volume dependent. $^{5}$

\section{HoLEP in Patients With Concomitant Bladder Diverticula}

The main cause of acquired bladder diverticula is bladder outlet obstruction ${ }^{30}$ and open diverticulectomy is preferred surgical procedure in symptomatic patients, but a retrospective study revealed that HoLEP is an effective treatment for bladder outlet obstruction in patients with bladder diverticula. In that study, 51 patients with bladder diverticula (mean size: $5.5 \pm 2.6 \mathrm{~cm}$ ) who underwent HoLEP were evaluated and more than 200\% improvement in PVR and urine peak flow within 12 months follow-up were reported and only $6 \%$ of patients required diverticulectomy in longer follow-up. ${ }^{31}$

\section{Anticoagulation}

The $\mathrm{BPH}$ surgery of patients who received an anticoagulant is a challenging issue because these patients are at higher risk of bleeding during an operation. On the other hand, discontinuing of anticoagulants increases the risk of thromboembolism accidents. Thus, perioperative anticoagulation management is on the basis of risk assessment for thromboembolism accidents and bleeding. ${ }^{32}$

Several studies have reported that HoLEP is a safe procedure in patients who receive anticoagulants, with no significant influence on the hemoglobin level. ${ }^{5}$

Literature indicated that the blood transfusion rate was significantly higher in patients who received anticoagulants $(9.4 \%$ vs. $4.4 \%, P<0.001)$, but in patients 
treated with antiplatelet agents, this trend was not significant $(2.9 \%$ in antiplatelet receiver vs. $5.7 \%$ in nonreceiver, $P=0.320) .{ }^{33}$

Despite HoLEP is feasible in choosing patients on an anticoagulant. Given the different mechanisms of action of anticoagulants, ${ }^{34}$ it seems to be incorrect to assume that the risk between different agents is similar.

In cases that a continuous anticoagulant agent is needed, preoperative bridging with low molecular weight heparin and postoperative resuming are typically safe. Some studies do not suggest HoLEP to patients in dual Antiplatelet therapy. The surgery of these patients should be postponed until at least one of the antiplatelet agents can be held with reasonable risk. ${ }^{5}$

Urologists have to consider that some drugs have interaction with platelet function, including Serotonin reuptake inhibitors ${ }^{19}$ that increase the risk of postoperative hemorrhage. ${ }^{35}$

\section{Retreatment After HoLEP}

The rate of retreatment due to adenoma regrowth in a seven-year follow-up after TURP was $17.7 \%$, but after HoLEP was $0 \%-1.4 \%$, suggesting that HoLEP is an excellent approach for BPH surgery. ${ }^{36,37}$

\section{HoLEP in the Re-Treatment Setting}

Elshal et al found that HoLEP was a technically practical and safe method for retreatment in patients with a prior history of prostate surgery and a need for retreatment because of adenoma regrowth. ${ }^{38}$ Marien et al showed that retreatment with HoLEP caused lower blood loss, shorter operation time and length of stay, and less tissue resected in comparison to primary treatment with HoLEP. Moreover, the risk of clot retention and urethral stricture is low in a re-treatment setting but significantly higher than the primary HoLEP. ${ }^{39}$

\section{Sexual Function}

One-third of men older than 50 years complain of simultaneous erectile dysfunction (ED) and LUTS/ $\mathrm{BPH} .{ }^{3,40}$ The influence of $\mathrm{BPH}$ surgery on erection function is controversial amongst urologists. ED was reported in $13 \%$ of the patients who underwent TURP. ${ }^{31-33}$ Some authors ${ }^{41}$ believe that ED is age-related, but others attribute it to preexisting ED. ${ }^{42}$ Hanbury et $\mathrm{al}^{43}$ propose that injury to the prostatic capsule and neurovascular bundles during an operation causes erectile dysfunction.

HoLEP is an effective surgical technique for treating $\mathrm{BPH},{ }^{27}$ with similar functional results to those of TURP and $\mathrm{OP}$ in terms of subjective symptom relief and urodynamic parameters and postoperative ED. ${ }^{36,44,45}$

Elshal et al compared PVP, HoLEP and holmium laser ablation of the prostate ${ }^{38}$ in terms of sexual dysfunction and they concluded that HoLEP group experienced more International Index of Erectile Function (IIEF) improvement $(41.4,60.6$, and $29.4 \%$ respectively). It could be due to lower total energy that was used during HoLEP, which resulted in diminishing damage to adjacent neurovascular tissues.

Patients with severe LUTS and a lower baseline IIEF score most likely benefit from HoLEP in terms of clinically significant erectile function improvement, regardless of their age. ${ }^{5}$

The bladder neck closure mechanism during ejaculation prevents the backward movement of semen into the bladder ${ }^{23,28}$ and the impairment of this mechanism after transurethral surgery for the prostate causes retrograde ejaculation. ${ }^{29}$

Kim et al reported that $76.9 \%$ of men experienced a total loss of ejaculation after HoLEP, $18.7 \%$ suffered from a decrease in ejaculation, and $4.4 \%$ had no change. ${ }^{46}$ Similar findings were reported by Briganti et al and these rates were quite similar to TURP. ${ }^{47}$ For patients with complete retrograde ejaculation, due to urinary function improvement, long-term sexual function was tolerable. ${ }^{46}$

\section{Post-HoLEP Urinary Incontinence}

Stress urinary incontinence (SUI) following BPH surgery may negatively influence patients' quality of life. It happens 3\%-9\% after OP, ${ }^{48,49}$ almost $2 \%$ after TURP, and $4.9 \%-12.5 \%$ after HoLEP, most of which recovered within one year. ${ }^{44,50,51}$

Diabetes mellitus, longer operation and enucleation time, surgeon's experience, larger prostate size, higher blood loss are some factors associated with SUI after HoLEP. ${ }^{52-54}$ Furthermore, the resection of tissue near the external sphincter might result in temporary UI. ${ }^{52-54}$

The modified bilobar approach of HoLEP decreased the incidence of retrograde ejaculation and UI, improving the patients' quality of life after surgery compared to the traditional three-lobe technology. ${ }^{19}$

Multivariate analysis revealed that the prostate transition zone volume was significantly associated with the early recovery of SUI. The patients with transition zone volume less than $30 \mathrm{~mL}$ may suffer from persistent stress urinary incontinence following HoLEP so other surgical techniques like bipolar TURP are a good choice for these patients. ${ }^{52}$

\section{Incidental Prostate Cancer}

A prostate biopsy is routinely performed to diagnose prostate cancer, but false negative results may be reported. ${ }^{55-58}$ Different from other laser therapy for $\mathrm{BPH}$, HoLEP is a surgical approach which provides a specimen for pathologic examination and therefore final specimen histology might disclose incidental prostate cancer (IPca). Despite preoperative prostate cancer risk assessment with biopsy, up to $13 \%$ of patients will be diagnosed with IPca following HoLEP. ${ }^{59,60}$

Several factors such as age, smaller prostate volume, PSA density and preoperative PSA were introduced as the predictors of IPca; however, PSA density and increased 
age are the independent predictors of IPca. ${ }^{5,61}$

Active surveillance, radical prostatectomy and radiotherapy are options for men diagnosed with IPca after HoLEP. Although active surveillance is appropriate for most patients, a proper surveillance regimen has not been recognized. Radical prostatectomy is another feasible choice, but the risk of incontinence and erectile dysfunction is higher. The outcomes of radiotherapy after HoLEP need further study. ${ }^{62}$

Gellhaus et al reported that only $27 \%$ of patients who underwent robotic-assisted laparoscopic prostatectomy after HoLEP developed with UI. Other oncologic parameters like the positive margin and the biochemical recurrence rate were similar to patients without a previous history of BPH surgery. ${ }^{63}$

In young patients with high PSA density and a negative standard template prostate biopsy that candidate for HoLEP, multiparametric MRI needs to be considered to exclude prostate cancer. This novel approach leads to low rates of incidental prostate cancer. ${ }^{63}$

\section{Comparison With TURP}

In comparison with TURP, HoLEP causes fewer blood loss and transfusions, a shorter catheter and hospital stay, but longer operation time. ${ }^{64,65}$

One meta-analysis revealed that between TURP and HoLEP, the rates of urethral stenosis ( $4.4 \%$ vs. $2.6 \%)$, stress urinary incontinence ( $1.5 \%$ vs. $1.5 \%)$, and re-intervention ( $8.8 \%$ vs. $4.3 \%$ ) were not significantly different. ${ }^{66}$

One randomized controlled trial (RCT) that compared HoLEP with TURP with a 7-year follow-up indicated sustained improvements beyond 7 years from the preoperative states of unhappiness and dissatisfaction to the pleased and delighted states. ${ }^{36}$ Another metaanalysis bolded the advantage of HoLEP when compared to TURP with regard to post-operative maximal flow. ${ }^{67}$ Similar results were seen whenever HoLEP and PVP were compared. ${ }^{68}$

A retrospective study with the longest follow-up (mean 62 months) reported durable functional results with low re-operation rates. ${ }^{69}$

A comprehensive meta-analysis showed that IPSS improvement after HoLEP is significantly better than TURP and these urinary function improvements (Qmax, PVR, and IPSS) are sustained beyond 5-10 years. ${ }^{36,70}$

Cornu et al showed a lower risk of bleeding in HoLEP compared with TURP due to the hemostatic properties of the surgical approach and thermal laser energy. ${ }^{71}$

Several RCTs showed that the operation time of HoLEP is significantly longer than OP, but it has a shorter catheter and hospital stay and fewer blood transfusions. Short-term and long-term urinary function, strictures, incontinence and reoperation after HoLEP are most similar to OP. ${ }^{27,28}$

\section{Learning Curve of HoLEP}

The main drawback of HoLEP is its steep learning curve.
A single-center experience showed that enucleation and morcellation efficiency was reached after 30 and 20 cases respectively and the complication rate, the operation time and the conversion rate decreased significantly with time. ${ }^{72}$ A systematic review including 24 studies and 5173 patients revealed that an acceptable learning curve based on different outcomes was reached with 25-50 cases. $^{73}$

\section{HoLEP Cost}

Another disadvantage of HoLEP is its cost that is higher than TURP (gold standard method). To determine the clinical effectiveness and cost-utility of an alternative procedure to TURP, a systematic review was conducted in 2008 and its results showed that HoLEP was more cost-effective than a single TURP but it was less effective than a strategy involving repeated TURP. Finally, it was concluded that TURP is clinically effective and costeffective. ${ }^{74}$

\section{HoLEP operation time}

Longer operation time is one of the disadvantages of HoLEP. In an RCT, Mavuduru et al revealed that HoLEP operation time is significantly higher than TURP (53 \pm 9.84 vs. $43 \pm 9.36 \mathrm{~min}$ respectively; $P=0.001)^{75}$ and this result was confirmed in a systematic review and the metaanalysis of RCTs in $2013 .{ }^{65}$ Furthermore, operation time in HoLEP is significantly higher than OP. ${ }^{28,76}$

\section{Conclusion}

In summary, HoLEP is an independent gland size technique for managing $\mathrm{BPH}$, which has some advantages including shorter catheterization time and hospital stay, fewer bleeding, a lower complication and reoperation rate. While operation time in HoLEP is often longer than TURP and OP, when analyzed by the grams of tissue removed per unit time, HoLEP is equivalent to $\mathrm{OP}$ and better than TURP. Despite some drawbacks including a steep learning curve, high cost and longer operation time, HoLEP can be used as a suitable alternative for any methods in different situations.

\section{Ethical Considerations}

Not applicable.

\section{Conflict of Interests}

None.

\section{Funding}

None.

\section{Acknowledgements}

We thank all the members of the department of urology and our hospital for their help.

\section{Reference}

1. Chute CG, Panser LA, Girman CJ, Oesterling JE, Guess 
HA, Jacobsen SJ, et al. The prevalence of prostatism: a population-based survey of urinary symptoms. J Urol. 1993;150(1):85-9. doi: 10.1016/s0022-5347(17)35405-8.

2. Guess HA, Arrighi HM, Metter EJ, Fozard JL. Cumulative prevalence of prostatism matches the autopsy prevalence of benign prostatic hyperplasia. Prostate. 1990;17(3):241-6. doi: 10.1002/pros.2990170308.

3. Karami H, Hassanzadeh-Hadad A, Fallah-Karkan M. Comparing monotherapy with tadalafil or tamsulosin and their combination therapy in men with benign prostatic hyperplasia: a randomized clinical trial. Urol J. 2016;13(6):2920-6. doi: 10.22037/uj.v13i6.3666.

4. Shigemura K, Fujisawa M. Current status of holmium laser enucleation of the prostate. Int J Urol. 2018;25(3):206-11. doi: 10.1111/iju.13507.

5. Marien T, Kadihasanoglu M, Miller NL. Holmium laser enucleation of the prostate: patient selection and perspectives. Res Rep Urol. 2016;8:181-92. doi: 10.2147/ RRU.S100245.

6. Razzaghi MR, Fallah Karkan M, Ghiasy S, Javanmard B. Laser application in iran urology: a narrative review. $J$ Lasers Med Sci. 2018;9(1):1-6. doi: 10.15171/jlms.2018.01.

7. Razzaghi MR, Mazloomfard MM, Mokhtarpour H, Moeini A. Diode laser $(980 \mathrm{~nm})$ vaporization in comparison with transurethral resection of the prostate for benign prostatic hyperplasia: randomized clinical trial with 2-year follow-up. Urology. 2014;84(3):526-32. doi: 10.1016/j. urology.2014.05.027.

8. Sadeghi K, Hamishehkar H, Najmeddin F, Ahmadi A, Hazrati E, Honarmand $\mathrm{H}$, et al. High-dose amikacin for achieving serum target levels in critically ill elderly patients. Infect Drug Resist. 2018;11:223-8. doi: 10.2147/ IDR.S150839.

9. Kahokehr AA, Gilling PJ. Which laser works best for benign prostatic hyperplasia? Curr Urol Rep. 2013;14(6):614-9. doi: 10.1007/s11934-013-0351-8.

10. Javanmard B, Fallah Karkan M, Razzaghi MR, Ghiasy S, Ranjbar A, Rahavian A. Surgical management of vesical stones in children: a comparison between open cystolithotomy, percutaneous cystolithotomy and transurethral cystolithotripsy with holmium-YAG Laser. J Lasers Med Sci. 2018;9(3):183-7. doi: 10.15171/ jlms.2018.33.

11. Abedi AR, Razzaghi MR, Allameh F, Aliakbari F, Fallahkarkan M, Ranjbar A. Pneumatic Lithotripsy Versus Laser Lithotripsy for Ureteral Stones. J Lasers Med Sci. 2018;9(4):233-6. doi: 10.15171/jlms.2018.42.

12. Ghiasy S, Fallah-Karkan M, Razzaghi MR, Ranjbar A, Rahavian A, Javanmard B. Is Holmium laser an appropriate modality to treat genital warts? J Lasers Med Sci. 2019;10(1):70-74. doi: 10.15171/jlms.2019.11.

13. Fallah Karkan M, Razzaghi MR, Karami H, Ghiasy S, Tayyebiazar A, Javanmard B. Experience of 138 transurethral urethrotomy with Holmium:YAG laser. J Lasers Med Sci. 2019;10(2):104-7. doi: 10.15171/jlms.2019.17.

14. Fallah Karkan M, Razzaghi MR, Javanmard B, Tayyebiazar A, Ghiasy S, Montazeri S. Holmium: YAG Laser Incision of Bladder Neck Contracture Following Radical Retropubic Prostatectomy. Nephro-Urol Mon. 2019;11(1):e88677. doi: 10.5812/numonthly.88677.

15. Mottet N, Anidjar M, Bourdon O, Louis JF, Teillac P,
Costa P, et al. Randomized comparison of transurethral electroresection and holmium: YAG laser vaporization for symptomatic benign prostatic hyperplasia. J Endourol. 1999;13(2):127-30. doi: 10.1089/end.1999.13.127.

16. Fallah Karkan M, Ghiasy S, Ranjbar A, Javanmard B. Evaluation of $200 \mathrm{Mm}, 365 \mathrm{Mm}$ and $500 \mathrm{Mm}$ fibers of Ho: YAG laser in transurethral lithotripsy of ureteral: a randomize control trial. J Lasers Med Sci. 2018;9(1):69-72. doi: 10.15171/jlms.2018.14.

17. Abedi AR, Allameh F, Razzaghi MR, Fadavi B, Qashqai H, Najafi S, et al. The efficacy and safety of laser lithotripsy in pregnancy. J Lasers Med Sci. 2017;8(2):84-7. doi: 10.15171/ jlms.2017.15.

18. Elshal AM, El-Nahas AR, Ghazy M, Nabeeh H, Laymon M, Soltan M, et al. Low-Power Vs High-Power Holmium Laser Enucleation of the Prostate: Critical Assessment through Randomized Trial. Urology. 2018;121:58-65. doi: 10.1016/j. urology.2018.07.010.

19. Xu C, Xu Z, Lin C, Feng S, Sun M, Chen J, et al. Holmium laser enucleation of the prostate: Modified two-Lobe technique versus traditional three-Lobe technique-A randomized study. Biomed Res Int. 2019;2019:3875418. doi: 10.1155/2019/3875418.

20. Kuo RL, Paterson RF, Kim SC, Siqueira TM Jr, Elhilali MM, Lingeman JE. Holmium Laser Enucleation of the Prostate (HoLEP): A Technical Update. World J Surg Oncol. 2003;1(1):6. doi: 10.1186/1477-7819-1-6.

21. Humphreys MR, Miller NL, Handa SE, Terry C, Munch LC, Lingeman JE. Holmium laser enucleation of the prostate-outcomes independent of prostate size? J Urol. 2008;180(6):2431-5. doi: 10.1016/j.juro.2008.08.019.

22. Shah HN, Sodha HS, Kharodawala SJ, Khandkar AA, Hegde SS, Bansal MB. Influence of prostate size on the outcome of holmium laser enucleation of the prostate. BJU Int. 2008;101(12):1536-41. doi: 10.1111/j.1464410X.2007.07434.x.

23. Seki N, Tatsugami K, Naito S. Holmium laser enucleation of the prostate: comparison of outcomes according to prostate size in 97 Japanese patients. J Endourol. 2007;21(2):192-6. doi: 10.1089/end.2006.0123.

24. Kim KS, Choi JB, Bae WJ, Kim SJ, Cho HJ, Hong SH, et al. Comparison of Photoselective Vaporization versus holmium laser enucleation for treatment of benign prostate hyperplasia in a small prostate volume. PLoS One. 2016;11(5):e0156133. doi: 10.1371/journal.pone.0156133.

25. Krambeck AE, Handa SE, Lingeman JE. Holmium laser enucleation of the prostate for prostates larger than 175 grams. J Endourol. 2010;24(3):433-7. doi: 10.1089/ end.2009.0147.

26. Matlaga BR, Kim SC, Kuo RL, Watkins SL, Lingeman JE. Holmium laser enucleation of the prostate for prostates of $>125$ mL. BJU Int. 2006;97(1):81-4. doi: 10.1111/j.1464410X.2006.05898.x.

27. Kuntz RM, Lehrich K, Ahyai SA. Holmium laser enucleation of the prostate versus open prostatectomy for prostates greater than 100 grams: 5-year follow-up results of a randomised clinical trial. Eur Urol. 2008;53(1):160-8. doi: 10.1016/j.eururo.2007.08.036.

28. Naspro R, Suardi N, Salonia A, Scattoni V, Guazzoni $\mathrm{G}$, Colombo R, et al. Holmium laser enucleation of the prostate versus open prostatectomy for prostates $>70$ 
g: 24-month follow-up. Eur Urol. 2006;50(3):563-8. doi: 10.1016/j.eururo.2006.04.003.

29. Wisenbaugh ES, Nunez-Nateras R, Mmeje CO, Warner JN, Humphreys MR. Does prostate morphology affect outcomes after holmium laser enucleation? Urology. 2013;81(4):844-8. doi: 10.1016/j.urology.2013.01.006.

30. Gerridzen RG, Futter NG. Ten-year review of vesical diverticula. Urology. 1982;20(1):33-5. doi: 10.1016/00904295(82)90532-5.

31. Agarwal DK, Krambeck AE. Holmium laser enucleation of the prostate is an effective treatment in patients with concomitant bladder diverticula and outlet obstruction. World J Urol. 2018;36(1):87-90. doi: 10.1007/s00345-0172114-5.

32. Douketis JD, Spyropoulos AC, Spencer FA, Mayr M, Jaffer AK, Eckman MH, et al. Perioperative management of antithrombotic therapy: antithrombotic therapy and prevention of thrombosis: American College of Chest Physicians evidence-based clinical practice guidelines. Chest. 2012;141(2 suppl):e326S-e350S. doi: 10.1378/ chest.11-2298.

33. Romero-Otero J, García-González L, García-Gómez B, Justo-Quintas J, García-Rojo E, González-Padilla DA, et al. Factors influencing intraoperative blood loss in patients undergoing Holmium Laser Enucleation of the Prostate (HoLEP) for Benign Prostatic Hyperplasia: a large multicenter analysis. Urology. 2019;132:177-182. doi: 10.1016/j.urology.2019.06.024.

34. De Caterina R, Husted S, Wallentin L, Andreotti F, Arnesen $\mathrm{H}$, Bachmann F, et al. General mechanisms of coagulation and targets of anticoagulants (section I). Position paper of the ESCworking group on thrombosis--task force on anticoagulants in heart disease. Thromb Haemost. 2013;109(4):569-79. doi: 10.1160/TH12-10-0772.

35. Dall M, Primdahl A, Damborg F, Nymark T, Hallas J. The association between use of serotonergic antidepressants and perioperative bleeding during total hip arthroplasty-a cohort study. Basic Clin Pharmacol Toxicol. 2014;115(3):27781. doi: 10.1111/bcpt.12218.

36. Gilling PJ, Wilson LC, King CJ, Westenberg AM, Frampton $\mathrm{CM}$, Fraundorfer MR. Long-term results of a randomized trial comparing holmium laser enucleation of the prostate and transurethral resection of the prostate: results at 7 years. BJU Int. 2012;109(3):408-11. doi: 10.1111/j.1464410X.2011.10359.x.

37. Gilling PJ, Aho TF, Frampton CM, King CJ, Fraundorfer MR. Holmium laser enucleation of the prostate: results at 6 years. Eur Urol. 2008;53(4):744-9. doi: 10.1016/j. eururo.2007.04.052.

38. Elshal AM, Elmansy HM, Elhilali MM. Feasibility of holmium laser enucleation of the prostate (HoLEP) for recurrent/residual benign prostatic hyperplasia (BPH). BJU Int. 2012;110(11 Pt C):E845-E50. doi: 10.1111/j.1464410X.2012.11290.x.

39. Marien T, Kadihasanoglu M, Tangpaitoon T, York $\mathrm{N}$, Blackburne A, Abdul-Muhsin $\mathrm{H}$, et al. MP42-08 Outcomes of HoLEP performed in the retreatment setting. J Urol. 2016;195(4S):e571-e572. doi.org/10.1016/j. juro.2016.12.098

40. Rosen R, Altwein J, Boyle P, Kirby RS, Lukacs B, Meuleman $\mathrm{E}$, et al. Lower urinary tract symptoms and male sexual dysfunction: the multinational survey of the aging male (MSAM-7). Eur Urol. 2003;44(6):637-49. doi: 10.1016/j. eururo.2003.08.015.

41. Soderdahl DW, Knight RW, Hansberry KL. Erectile dysfunction following transurethral resection of the prostate. J Urol. 1996;156(4):1354-6. doi: 10.1016/S00225347(01)65585-X.

42. Tscholl R, Largo M, Poppinghaus E, Recker F, Subotic B. Incidence of erectile impotence secondary to transurethral resection of benign prostatic hyperplasia, assessed by preoperative and postoperative Snap Gauge tests. J Urol. 1995;153(5):1491-3. doi: 10.1016/S0022-5347(01)67442-1.

43. Hanbury DC, Sethia KK. Erectile function following transurethral prostatectomy. Br J Urol. 1995;75(1):12-3. doi: 10.1111/j.1464-410x.1995.tb07224.x.

44. Montorsi F, Naspro R, Salonia A, Suardi N, Briganti $\mathrm{A}$, Zanoni $\mathrm{M}$, et al. Holmium laser enucleation versus transurethral resection of the prostate: results from a 2-center prospective randomized trial in patients with obstructive benign prostatic hyperplasia. J Urol. 2008;179(5 Suppl):S87-S90. doi: 10.1016/j.juro.2008.03.143.

45. Naspro R, Bachmann A, Gilling P, Kuntz R, Madersbacher $\mathrm{S}$, Montorsi $\mathrm{F}$, et al. A review of the recent evidence (2006-2008) for 532-nm photoselective laser vaporisation and holmium laser enucleation of the prostate. Eur Urol. 2009;55(6):1345-57. doi: 10.1016/j.eururo.2009.03.070.

46. Kim JK, Cho MC, Son H, Ku JH, Oh S-J, Paick JS. Patient perception of ejaculatory volume reduction after holmium laser enucleation of the prostate (HoLEP). Urology. 2017;99:142-7. doi: 10.1016/j.urology.2016.09.037.

47. Briganti A, Naspro R, Gallina A, Salonia A, Vavassori I, Hurle R, et al. Impact on sexual function of holmium laser enucleation versus transurethral resection of the prostate: results of a prospective, 2-center, randomized trial. J Urol. 2006;175(5):1817-21. doi: 10.1016/S0022-5347(05)009833.

48. Serretta V, Morgia G, Fondacaro L, Curto G, Lo bianco A, Pirritano D, et al. Open prostatectomy for benign prostatic enlargement in southern Europe in the late 1990s: a contemporary series of 1800 interventions. Urology. 2002;60(4):623-7. doi: 10.1016/s0090-4295(02)01860-5.

49. Tubaro A, Carter S, Hind A, Vicentini C, Miano L. A prospective study of the safety and efficacy of suprapubic transvesical prostatectomy in patients with benign prostatic hyperplasia. J Urol. 2001;166(1):172-6. doi: 10.1016/S00225347(05)66102-2.

50. Kuntz RM, Lehrich K, Ahyai S. Does perioperative outcome of transurethral holmium laser enucleation of the prostate depend on prostate size? J Endourol. 2004;18(2):183-8. doi: 10.1089/089277904322959842.

51. Seki N, Mochida O, Kinukawa N, Sagiyama K, Naito $\mathrm{S}$. Holmium laser enucleation for prostatic adenoma: analysis of learning curve over the course of 70 consecutive cases. J Urol. 2003;170(5):1847-50. doi: 10.1097/01. ju.0000092035.16351.9d.

52. Cho KJ, Koh JS, Choi JB, Kim JC. Factors associated with early recovery of stress urinary incontinence following holmium laser enucleation of the prostate in patients with benign prostatic enlargement. Int Neurourol J. 2018;22(3):200-205. doi: 10.5213/inj.1836092.046.

53. Endo F, Shiga Y, Minagawa S, Iwabuchi T, Fujisaki A, Yashi 
M, et al. Anteroposterior dissection HoLEP: a modification to prevent transient stress urinary incontinence. Urology. 2010;76(6):1451-5. doi: 10.1016/j.urology.2010.03.071.

54. Walz J, Burnett AL, Costello AJ, Eastham JA, Graefen $\mathrm{M}$, Guillonneau B, et al. A critical analysis of the current knowledge of surgical anatomy related to optimization of cancer control and preservation of continence and erection in candidates for radical prostatectomy. Eur Urol. 2010;57(2):179-92. doi: 10.1016/j.eururo.2009.11.009.

55. Jones JS. Saturation biopsy for detecting and characterizing prostate cancer. BJU Int. 2007;99(6):1340-4. doi: 10.1111/j.1464-410X.2007.06868.x.

56. Serefoglu EC, Altinova S, Ugras NS, Akincioglu E, Asil E, Balbay MD. How reliable is 12-core prostate biopsy procedure in the detection of prostate cancer? Can Urol Assoc J. 2013;7(5-6):E293-8. doi: 10.5489/cuaj.11224.

57. Abedi AR, Fallah-Karkan M, Allameh F, Ranjbar A, Shadmehr A. Incidental prostate cancer: a 10-year review of a tertiary center, Tehran, Iran. Res Rep Urol. 2018;10:1-6. doi: 10.2147/RRU.S146159.

58. Jamali L, Moradi A, Ganji M, Ayati M, Kazeminezhad B, Fazeli Attar Z, et al. Potential Prognostic Role for SPOP, DAXX, RARRES1, and LAMP2 as an Autophagy Related Genes in Prostate Cancer. Urol J. 2019. doi: 10.22037/ uj.v0i0.4935.

59. Rivera ME, Frank I, Viers BR, Rangel LJ, Krambeck AE. Holmium laser enucleation of the prostate and perioperative diagnosis of prostate cancer: an outcomes analysis. J Endourol. 2014;28(6):699-703. doi: 10.1089/ end.2014.0009.

60. Elkoushy MA, Elshal AM, Elhilali MM. Incidental prostate cancer diagnosis during holmium laser enucleation: assessment of predictors, survival, and disease progression. Urology. 2015;86(3):552-7. doi: 10.1016/j. urology.2015.06.002.

61. Ghiasy S, Abedi AR, Moradi A, Hosseini SY, Karkan MF, Sadri $\mathrm{G}$, et al. Is active surveillance an appropriate approach to manage prostate cancer patients with Gleason Score 3+3 who met the criteria for active surveillance? Turk J Urol. 2018;45(4):261-4. doi: 10.5152/tud.2018.72920.

62. Porreca A, Giampaoli M, Bianchi L, D’Agostino D, Romagnoli D, Bianchi FM, et al. Preoperative multiparametric prostate magnetic resonance imaging: a safe clinical practice to reduce incidental prostate cancer in Holmium laser enucleation of the prostate. Cent European J Urol.2019;72(2):106-112. doi: 10.5173/ceju.2019.1943.

63. Gellhaus PT, Monn MF, Leese J, Flack CK, Lingeman JE, Koch MO, et al. Robot-assisted radical prostatectomy in patients with a history of holmium laser enucleation of the prostate: feasibility and evaluation of initial outcomes. J Endourol. 2015;29(7):764-9. doi: 10.1089/end.2014.0767.

64. Tan A, Liao C, Mo Z, Cao Y. Meta-analysis of holmium laser enucleation versus transurethral resection of the prostate for symptomatic prostatic obstruction. Br J Surg. 2007;94(10):1201-8. doi: 10.1002/bjs.5916.

65. Yin L, Teng J, Huang CJ, Zhang X, Xu D. Holmium laser enucleation of the prostate versus transurethral resection of the prostate: a systematic review and meta-analysis of randomized controlled trials. J Endourol. 2013;27(5):604-

\section{1. doi: 10.1089/end.2012.0505.}

66. Naqvi SA, Rizvi S, Hasan A. High-energy microwave thermotherapy in patients in urinary retention. J Endourol. 2000;14(8):677-81. doi: 10.1089/end.2000.14.677.

67. Ahyai SA, Gilling P, Kaplan SA, Kuntz RM, Madersbacher $\mathrm{S}$, Montorsi F, et al. Meta-analysis of functional outcomes and complications following transurethral procedures for lower urinary tract symptoms resulting from benign prostatic enlargement. Eur Urol. 2010;58(3):384-97. doi: 10.1016/j.eururo.2010.06.005.

68. Elmansy H, Baazeem A, Kotb A, Badawy H, Riad E, Emran A, et al. Holmium laser enucleation versus photoselective vaporization for prostatic adenoma greater than 60 $\mathrm{ml}$ : preliminary results of a prospective, randomized clinical trial. J Urol. 2012;188(1):216-21. doi: 10.1016/j. juro.2012.02.2576.

69. Elmansy HM, Kotb A, Elhilali MM. Holmium laser enucleation of the prostate: long-term durability of clinical outcomes and complication rates during 10 years of followup. J Urol. 2011;186(5):1972-6. doi: 10.1016/j. juro.2011.06.065.

70. Gupta N, Sivaramakrishna, Kumar R, Dogra PN, Seth A. Comparison of standard transurethral resection, transurethral vapour resection and holmium laser enucleation of the prostate for managing benign prostatic hyperplasia of $>40$ g. BJU Int. 2006;97(1):85-9. doi: 10.1111/j.1464-410X.2006.05862.x.

71. Cornu JN, Ahyai S, Bachmann A, de la Rosette J, Gilling P, Gratzke C, et al. A systematic review and metaanalysis of functional outcomes and complications following transurethral procedures for lower urinary tract symptoms resulting from benign prostatic obstruction: an update. Eur Urol. 2015;67(6):1066-96. doi: 10.1016/j. eururo.2014.06.017.

72. Bae J, Oh SJ, Paick JS. The learning curve for holmium laser enucleation of the prostate: a single-center experience. Korean J Urol. 2010;51(10):688-93. doi: 10.4111/ kju.2010.51.10.688.

73. Kampantais MS, Dimopoulos MP, Tasleem MA, Acher MP, Gordon MK, Young A. Assessing the learning curve of Holmium Laser Enucleation of Prostate (HoLEP). A systematic review. Urology. 2018. doi: 10.1016/j. urology.2018.06.012.

74. Lourenco T, Armstrong N, N'Dow J, Nabi G, Deverill M, Pickard R, et al. Systematic review and economic modelling of effectiveness and cost utility of surgical treatments for men with benign prostatic enlargement. Health Technol Assess. 2008;12(35):iii, ix-x, 1-146, 169-515. doi: 10.3310/ hta12350.

75. Mavuduru RM, Mandal AK, Singh SK, Acharya N, Agarwal $\mathrm{M}$, Garg S, et al. Comparison of HoLEP and TURP in terms of efficacy in the early postoperative period and perioperative morbidity. Urol Int. 2009;82(2):130-5. doi: $10.1159 / 000200786$.

76. Kuntz RM, Lehrich K, Ahyai S. Transurethral holmium laser enucleation of the prostate compared with transvesical open prostatectomy: 18-month follow-up of a randomized trial. J Endourol. 2004;18(2):189-91. doi: $10.1089 / 089277904322959851$. 